\title{
PIDsthat Work
}

$\mathbf{R}$

esearchers from the NIOSH Alaska Pacific Office conducted an evaluation with commercial fishermen from 4 gear groups to rate the comfort and acceptability of six modern personal flotation devices (PFDs)? About 200 fishermen were asked to evaluate a PFD for one month while working on deck so that wearable PFDs could be identified. This document shows which PFDs were preferred by crabbers.

\section{PFD Use Among Crabbers:}

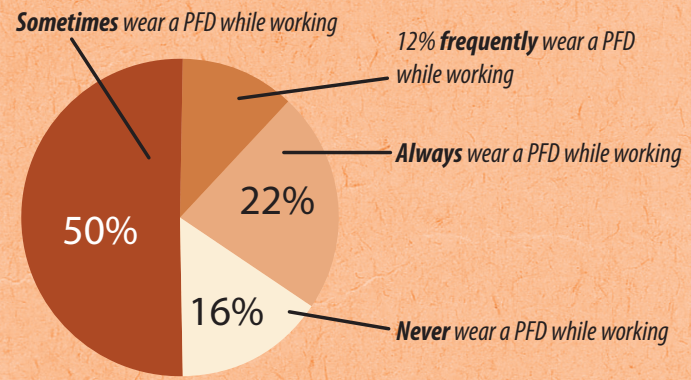

\section{Crabbers' Responses to Survey:}

- Over half of the crabbers said they knew someone who had died from a fall overboard

- $60 \%$ of crabbers believed PFDs are effective at saving lives

- Most crabbers didn't think that PFDs are uncomfortable or interfere with work, although half of them thought PFDs could be an entanglement hazard

\section{PFD Evaluation:}

After the 30 day on deck evaluation of PFDs, crabbers preferred Mustang and Stearns Inflatable Suspenders. Comments on the devices include:

- Did not constrict motion or snag on gear

- Did not interfere with their work

- Were rated as comfortable to wear because they were not tight or bulky
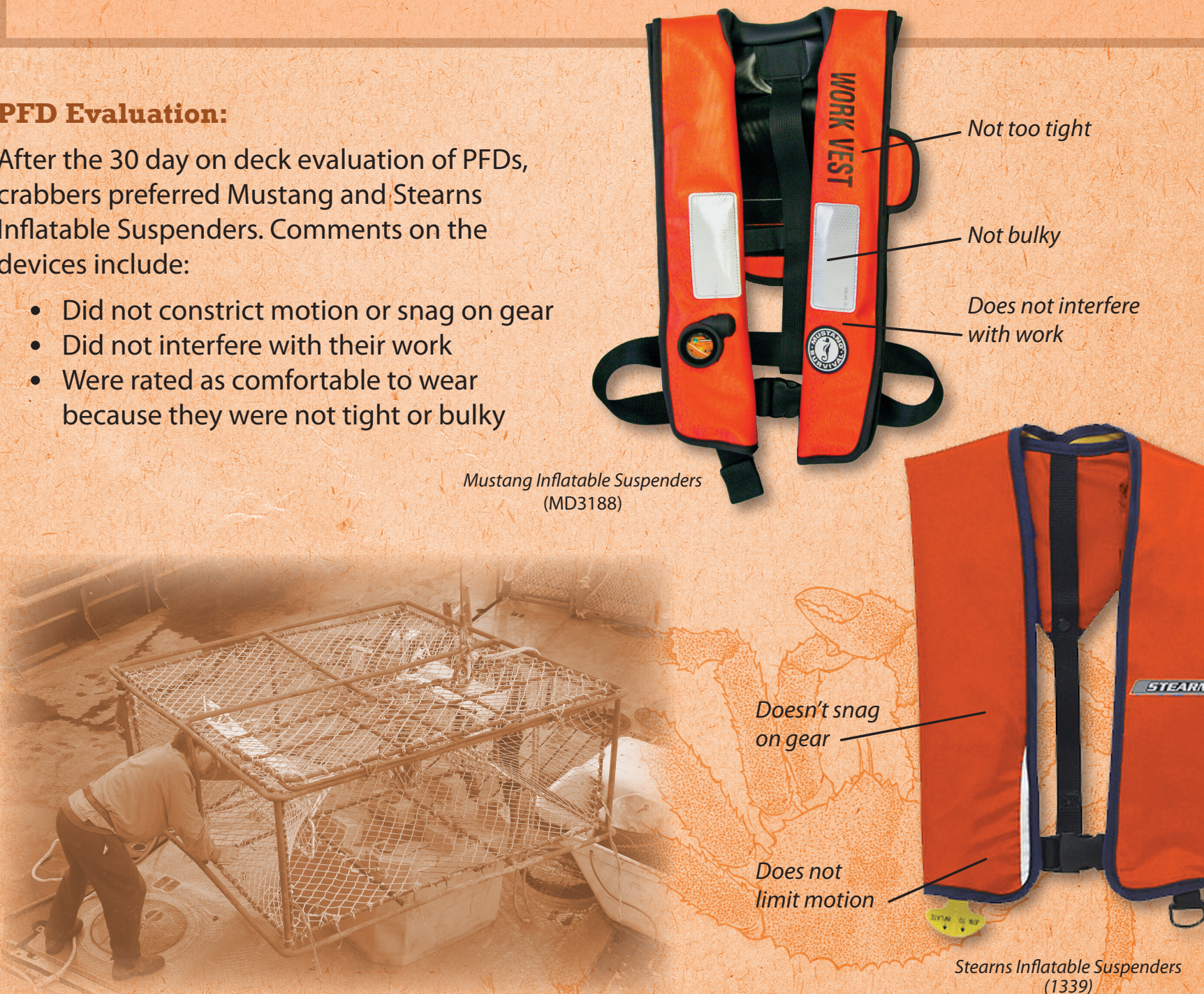


\section{Background on PFD Study in Alaska Fisheries}

very year fishermen die from falling overboard; it is the second leading cause of death for Fishermen nationwide. From 2000 to 2011, 182 U.S. commercial fishermen drowned after falling overboard. None of the workers were wearing a Personal Flotation Device (PFD), and many were within minutes of being rescued when they lost their strength, sank, and drowned. Those deaths could have been prevented if the fishermen had been wearing a PFD.

Marine safety experts have learned that some of the most common objections to wearing a PFD are that they are bulky,

Personal Flotation Devices Prevent Fishermen Deaths heavy, hot, and generally uncomfortable. Fishermen have also expressed concerns that PFDs could snag on fishing gear. After a 30-day evaluation of PFDs among 4 gear types (crabbers, trawlers, longliners, and gillnetters) these objections were addressed through selecting the proper PFDs.

\section{Recommendations for all Fishermen}

There are many models and styles of PFDs available today that are designed for commercial fishing. When choosing a PFD try on a variety of styles and models to find the one that works best for the type of work to be done.

The best PFD is the one that is worn on deck!

All vessel operators should have a PFD policy for their crew. Examples of PFD polices include:

- PFDs must be worn $100 \%$ of the time on deck

- PFDs must be worn when climbing the stack

- PFDs must be worn when crossing a river bar

- PFDs must be worn when the weather turns bad

Whatever your policy is, write it down, post it, and make the crew aware of it.

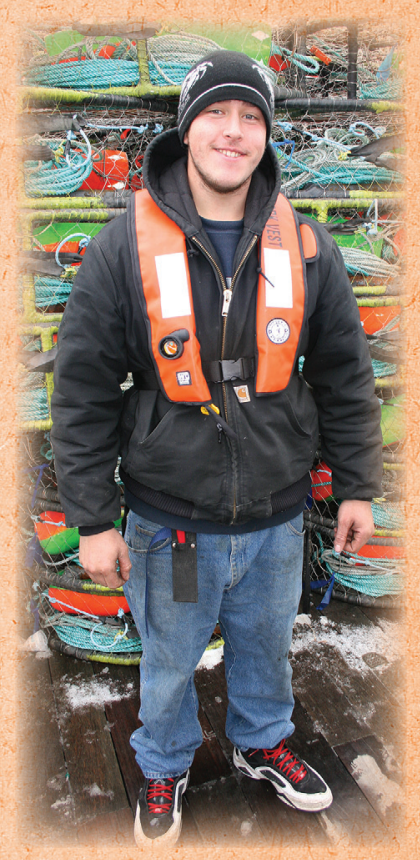

\section{SAFER・HEALTHIER・PEOPLE}

U.S. Department of Health and Human Services

Centers for Disease Control and Prevention

National Institute for Occupational Safety and Health

To receive NIOSH documents or more information about occupational safety and health topics, please contact NIOSH. Telephone: 1-800-CDC-INF0 (1-800-232-4636) |TTY: 1-888-232-6348 | email: cdcinfo@cdc.gov|www.cdc.gov/niosh For a monthly update on news at NIOSH, subscribe to NIOSH eNews by visiting www.cdc.gov/niosh/eNews.

DHHS (NIOSH) Publication Number: 2013-106, November 2012

'Lucas, D., Lincoln, J., Somervell, P., \& Teske, T. (2012). Worker satisfaction with personal flotation devices (PFDs) in the fishing industry: Evaluations in actual use. Appl Ergon, 43, 747-752.

The use of trade names and commercial sources is for identification purposes only and does not imply endorsement by the National Institute for Occupational Safety and Health (NIOSH), the Centers for Disease Control and Prevention (CDC), or the U.S. Department of Health and Human Services (HHS) or imply that one product is preferred by NIOSH, CDC, or HHS over other products manufactured by other companies. The products identified in this brochure are based on the results of the study referenced below which was designed to identify barriers and objections to PFD use and highlight the PFD features preferred by study participants. Six PFD products of varying styles and features were evaluated by commercial fishermen from different vessel types.

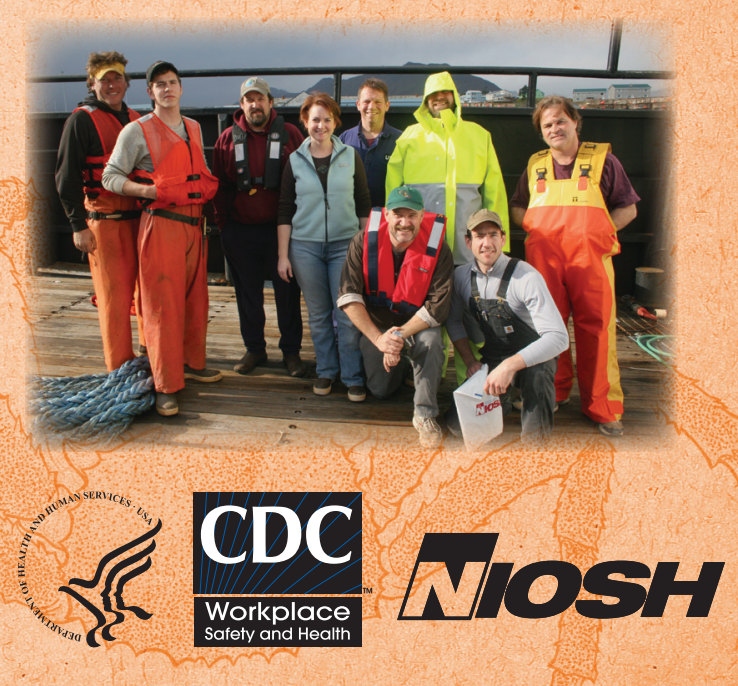

For more information on commercial fishing safety research at NIOSH visit: www.cdc.gov/niosh/topics/fishing 